\title{
BLM Protein Variant
}

National Cancer Institute

\section{Source}

National Cancer Institute. BLM Protein Variant. NCI Thesaurus. Code C131465.

A variation in the amino acid sequence for Bloom syndrome protein. 